NOTE

\title{
Antibodies against Discocotyle sagittata (Monogenea) in farmed trout
}

\author{
Miguel Rubio-Godoy ${ }^{1, *}$, Jens Sigh $^{2}$, Kurt Buchmann ${ }^{2}$, Richard C. Tinsley $^{1}$ \\ ${ }^{1}$ School of Biological Sciences, University of Bristol, Bristol BS8 1UG, UK \\ ${ }^{2}$ Department of Veterinary Microbiology, Section of Fish Diseases, Royal Veterinary and Agricultural University, 4 Stigbøjlen, \\ 1870 Frederiksberg C., Denmark
}

\begin{abstract}
The relationship between Discocotyle sagittata intensities and host length, weight and specific anti-parasite antibody titres was studied in 3 year-classes of farmed rainbow trout Oncorhynchus mykiss and brown trout Salmo trutta at the end of the annual transmission cycle. Antibody titres were significantly higher in infected farmed fish than in naïve controls, indicating that infection elicits immunoglobulin production. No correlation was found between host size and parasite burdens, nor between infection intensities and antibody titres.
\end{abstract}

KEY WORDS: Trout - Oncorhynchus mykiss $\cdot$ Salmo trutta Monogenea $\cdot$ Discocotyle sagittata $\cdot$ Antibodies

Resale or republication not permitted without written consent of the publisher

Discocotyle sagittata is a monogenean parasite infecting freshwater salmonid fishes with a wide distribution in the northern hemisphere (Williams \& Jones 1994). In common with other monogeneans (Thoney \& Hargis 1991), D. sagittata occurs at low prevalence and intensity in wild fish, but can reach pathogenic levels of infection in farmed fishes. Temperature is the main abiotic factor affecting its development, which is virtually arrested with water temperatures $<10^{\circ} \mathrm{C}$ (Gannicott \& Tinsley 1997, 1998a,b). This results in clear annual transmission cycles: no infections occur during the winter, while transmission is continuous during the summer and until late autumn. Knowledge of $D$. sagittata biology enabled the establishment of a dependable experimental infection system (Rubio-Godoy \& Tinsley 2002). In laboratory trials, rainbow trout were partially protected against controlled challenges following immunisation with $D$. sagittata extracts, and a significant negative correlation was found between antibody levels and parasite numbers recovered from immunised fish (Rubio-Godoy et al. 2003). This study aimed to determine whether infection under farm conditions induced the production of specific antiparasite antibodies.
Materials and methods. Fish: Fish examined for the present investigation were raised in a fish farm in the Isle of Man, British Isles, where different year-classes and fish species were kept in separate ponds. Fish were weighed and measured after anaesthesia (MS-222), exsanguinated via the caudal vein, and the gills dissected and preserved in formalin for later analysis. In a survey at the end of the yearly transmission cycle in late November 2001, 20 rainbow trout Oncorhynchus mykiss from each of the $0+, 1+$ and $2+$ yr classes were sampled; brown trout Salmo trutta samples consisted of $17 \times 0+, 20$ $\times 1+$ and $10 \times 2+$ yr class fish. Naïve fish used as controls came from a parasite-free farm in Denmark.

Infection levels: To calculate the mean parasite intensity (Bush et al. 1997), Discocotyle sagittata were recovered from the gills under a dissecting microscope. Parasite development was determined by counting the number of clamps present on the haptor; a mean developmental index (DI) was calculated for worms from individual fish, and mean DI are reported for each fish year-class (Rubio-Godoy \& Tinsley 2002). DI values range from 1 for freshly attached worms with 1 pair of clamps, to 4.5 for sexually mature worms with 4 pairs of clamps.

Antibody titres: Blood samples were allowed to clot overnight at $4^{\circ} \mathrm{C}$ and sera were frozen $\left(-70^{\circ} \mathrm{C}\right)$ until processed. Antibody titres were determined by ELISA, as described previously (Rubio-Godoy et al. 2003). Briefly, sonicated worms were used as antigenic source and each plate included 2 controls: blank wells (no primary antibodies from farmed fish) and sera from naïve fish, which were the same, irrespective of the year-class analysed. Sera were diluted serially up to a factor of $2^{13}$ (1:8194) and analysed using rabbit anti-salmon immunoglobulin (Buchmann \& Pedersen 1994) as secondary, and peroxidase-conjugated goat anti-rabbit immunoglobulin [Sigma] as tertiary antibodies; values 
greater than 2 times the (blank) background absorbance were considered to be positive. Titres are reported as the 2 -fold dilution factor beyond which no response was detected. Results were validated against optical density readings at $492 \mathrm{~nm}$ obtained from naïve sera, which were the same in the different plates/assay lots (RubioGodoy et al. 2003).

Statistics: Worm intensities were compared with Kruskal-Wallis tests. Antibody titres and ELISA tests were analysed by 1-way ANOVA plus Tukey's post-hoc tests. Pearson correlations between parasite intensity and antibody titres, fish weight and length were calculated. Calculations were carried out with SPSS for Windows 10.0; the significance level was set at $\mathrm{p}<0.05$.

Results. Fish host and Discocotyle sagittata infectioncharacteristics are shown in Table 1. Prevalence of infection was $>50 \%$ in all cases, and the mean intensities were significantly different between fish year-classes. The mean parasite DI calculated for each fish year-class shows the majority of parasites were at or approaching sexual maturity (value 4.5); however, the DI range found (1 to 4.5) indicates that worms from all developmental stages were present. Fig. 1 illustrates the specific anti-D. sagittata immunoglobulin titres determined for individual fish, as well as the correlation between these and parasite intensities. Mean antibody titres (detectable 2-fold dilution factors) \pm SE for different year-classes $(0+, 1+$ and $2+)$ were as follows: $0+$ rainbow trout $(\mathrm{RT}), 8.0 \pm 0.48 ; 1+\mathrm{RT}, 9.4 \pm 0.53 ; 2+\mathrm{RT}$, $8.7 \pm 0.57 ; 0+$ brown trout $(\mathrm{BT}), 8.8 \pm 0.49 ; 1+\mathrm{BT}, 10.6 \pm$ $0.67 ; 2+\mathrm{BT}, 7.7 \pm 0.52$. ELISA tests were validated by ANOVA, demonstrating that OD readings from naïve fish were comparable in all plates. Most fish presented higher antibody titres than naïve fish (mean titre \pm SE of $5.8 \pm 0.40$ ); the mean titres determined for farmed fish were all significantly different from naïve controls. 1+ BT antibody titres were the highest overall, and significantly different from all other groups except 1+ RT. No significant correlation was found between fish length/ weight and parasite intensity and antibody titre. The parasite intensity-antibody titre correlation was also not significant in all fish year-classes.
Discussion. The present study provides evidence for the occurrence in farmed trout of high antibody titres against the gill-inhabiting ectoparasite Discocotyle sagittata. Similarly, antibodies have been detected in carp against the monogenean Dactylogyrus vastator (Vladimirov 1971), in tiger puffer against Heterobothrium okamotoi (Wang et al. 1997), and in eels against Pseudodactylogyrus bini (Buchmann 1993) and $P$. anguillae (Mazzanti et al. 1999). In contrast, no elevated immunoglobulin levels were found in Leiostomus xanthurus infected with Heteraxinoides xanthophilis (Thoney \& Burreson 1988), Japanese flounder harbouring Neobenedenia girellae (Bondad-Reantaso et al. 1995), nor in rainbow trout infected with Gyrodactylus derjavini (Buchmann 1998). In Oncorhynchus mykiss, immunisation with D. sagittata extracts conferred partial protection and elicited the production of significant titres of antibodies; these correlated negatively with parasite burdens following controlled exposure, suggesting they may mediate protection (RubioGodoy et al. 2003).

In this study, elevated specific anti-parasite immunoglobulin titres were found in the 3 year-classes of both rainbow and brown trout. Despite quite different parasite burdens, antibody titres were comparable between rainbow and brown trout of the same age class, but no correlation was found between infection intensity and immunoglobulin levels in individual fish. Blood samples were obtained in November, towards the end of the annual transmission season. This probably facilitated the assessment of humoral immunity, because (1) parasite exposure would have been maximal, with invasion occurring continuously for the previous 6 mo since late May/early June; and (2) during summer, fish would have experienced optimal temperatures favouring the development of humoral immunity (Alcorn et al. 2002). Continuous transmission throughout the summer was confirmed in this survey by the presence of parasites in all stages of development. Field records (Rubio-Godoy \& Tinsley unpubl.) indicate that fish-of-the-year (0+ fish) harbour no parasites at the beginning of the annual transmission cycle

Table 1. Descriptive statistics of farmed rainbow trout Oncorhynchus mykiss (RT) and brown trout Salmo trutta (BT) infected with Discocotyle sagittata. DI = developmental index calculated for parasites from individual fish

\begin{tabular}{|c|c|c|c|c|c|c|}
\hline Fish year-class & $\mathrm{n}$ & $\begin{array}{l}\text { Mean length } \\
(\mathrm{cm} \pm \mathrm{SE})\end{array}$ & $\begin{array}{l}\text { Mean weight } \\
\qquad(g \pm \mathrm{SE})\end{array}$ & $\begin{array}{c}\text { Prevalence } \\
\text { of infection (\%) }\end{array}$ & $\begin{array}{l}\text { Mean parasite } \\
\text { intensity } \pm \mathrm{SE}\end{array}$ & $\begin{array}{l}\text { Mean DI } \\
\text { (range) }\end{array}$ \\
\hline $0+\mathrm{RT}$ & 20 & $14.6 \pm 0.3$ & $39.1 \pm 2.2$ & 85 & $2.5 \pm 0.3$ & $3.8(1-4.5)$ \\
\hline $1+\mathrm{RT}$ & 20 & $27.0 \pm 0.3$ & $220.6 \pm 8.5$ & 100 & $19.5 \pm 1.6$ & $3.7(1-4.5)$ \\
\hline $2+\mathrm{RT}$ & 20 & $37.3 \pm 0.4$ & $690.1 \pm 29.5$ & 100 & $132.4 \pm 17.0$ & $2.7(1-4.5)$ \\
\hline $0+\mathrm{BT}$ & 17 & $13.4 \pm 0.4$ & $30.4 \pm 2.5$ & 88 & $11.0 \pm 2.6$ & $3.4(1-4.5)$ \\
\hline $1+\mathrm{BT}$ & 20 & $27.8 \pm 0.4$ & $256.2 \pm 12.3$ & 55 & $2.5 \pm 0.4$ & $2.6(1.5-4.5)$ \\
\hline $2+\mathrm{BT}$ & 10 & $42.6 \pm 0.8$ & $1026.9 \pm 63.1$ & 100 & $34.1 \pm 7.1$ & $3.2(1-4.5)$ \\
\hline
\end{tabular}



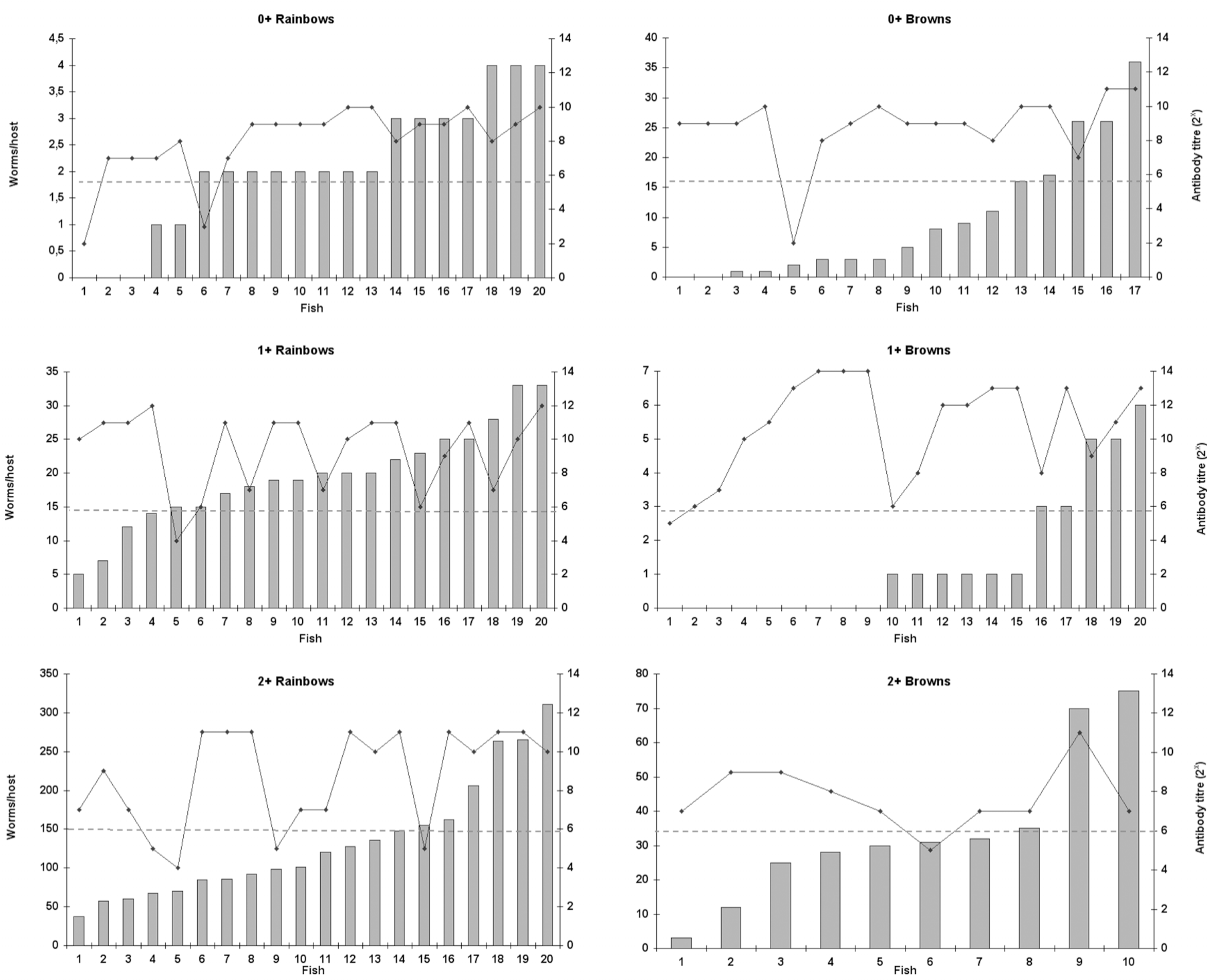

Fig. 1. Correlation between Discocotyle sagittata burdens and parasite-specific antibody titres (reciprocal dilution factors) in individual rainbow trout Oncorhynchus mykiss (rainbows) and brown trout Salmo trutta (browns) from different year-classes (0+, $1+, 2+)$. Dashed line across graphs represents the mean antibody titres detected in naïve controls. Note that the antibody titre axis is the same for all graphs, but the intensity axis differs

in May, and present ca. $85 \%$ prevalence of Discocotyle sagittata infection when sampled in November, suggesting most fish would have been exposed to parasites during their first summer. Significant antibody titres found in $0+$ fish indicate that their production can be elicited in response to natural infection, despite relatively low parasite intensities $(2.5$ and 11 worms per infected host for rainbow and brown trout, respectively). However, parasite intensity towards the end of the transmission season may only represent a fraction of the overall antigenic stimulus potentially created by the exposure of fish to infective larvae. Older fish likewise presented high immunoglobulin levels, with the overall highest titre (dilution factor 14) found in 1+ BT bearing no worms (almost half of the sample; Fig. 1). Nonetheless, considering the absence of a significant correlation between parasite burdens and antibody titres, and the fact that we only analysed one time point of the dynamic host-parasite interaction, the precise role of immunoglobulin cannot be established, since it is unknown whether fish with elevated immunoglobulin titres had cleared previous infections, or were never infected. However, given that almost all fish became infected under the maintenance regime at the farm, it is most likely that older fish found uninfected had eliminated their worm burdens. It must be emphasised 
that, in this study, parasite intensities do not necessarily reflect differences in immune-mediated control of worm numbers, because rainbow and brown trout were kept in different ponds and may have been exposed to distinct infective pressures.

Absolutely parasite-free naïve fish have detectable antibodies against Discocotyle sagittata, which could be due to naturally occurring immunoglobulin with low affinity to this parasite. Alternatively, cross reactivity to other parasites might account for detectable antiparasite immunoglobulin levels. Nonetheless, no helminth parasites other than $D$. sagittata were found over a 3 yr study in the farm where the fish came from. Moreover, fishes from the 3 year-classes analysed had significantly higher immunoglobulin titres than naïve controls, demonstrating that, under farming conditions, rainbow and brown trout do produce antibodies against Discocotyle sagittata.

Acknowledgements. We thank J. Ballard for access to fish and lab facilities in the Isle of Man. M.R.-G is supported by CONACYT (Mexico) \& ORS (UK) postgraduate scholarships. This work was in part conducted in connection with the SCOFDA network supported by the Danish Agricultural and Veterinary Research Council.

\section{LITERATURE CITED}

Alcorn SW, Murray AL, Pascho RJ (2002) Effects of rearing temperature on immune functions in sockeye salmon (Oncorhynchus nerka). Fish Shellfish Immunol 12: 303-334

Bondad-Reantaso MG, Ogawa K, Yoshinaga T, Wakabayashi $\mathrm{H}$ (1995) Acquired protection against Neobenedenia girellae in Japanese flounder. Fish Pathol 30:233-238

Buchmann K (1993) A note on the humoral immune response of infected Anguilla anguilla against the gill monogenean Pseudodactylogyrus bini. Fish Shellfish Immunol 3: 397-399

Editorial responsibility: Wolfgang Körting,

Hannover, Germany
Buchmann K (1998) Binding and lethal effect of complement from Oncorhynchus mykiss on Gyrodactylus derjavini (Platyhelminthes: Monogenea). Dis Aquat Org 32: 195-200

Buchmann K, Pedersen K (1994) A study on teleost phylogeny using specific antisera. J Fish Biol 45:901-903

Bush AO, Lafferty KD, Lotz JM, Shostak AW (1997) Parasitology meets ecology on its own terms: Margolis et al. revisited. J Parasitol 83:575-583

Gannicott AM, Tinsley RC (1997) Egg hatching in the monogenean gill parasite Discocotyle sagittata from the rainbow trout (Oncorhynchus mykiss). Parasitology 114: 569-579

Gannicott AM, Tinsley RC (1998a) Larval survival characteristics and behaviour of the gill monogenean Discocotyle sagittata. Parasitology 117:491-498

Gannicott AM, Tinsley RC (1998b) Environmental effects on transmission of Discocotyle sagittata (Monogenea): egg production and development. Parasitology 117:499-504

Mazzanti C, Monni G, Varriale AMC (1999) Observations on antigenic activity of Pseudodactylogyrus anguillae (Monogenea) on the European eel (Anguilla anguilla). Bull Eur Assoc Fish Pathol 19:57-59

Rubio-Godoy M, Tinsley RC (2002) Trickle and single infection with Discocotyle sagittata (Monogenea: Polyopisthocotylea): effect of exposure mode on parasite abundance and development. Folia Parasitol 49:269-278

Rubio-Godoy M, Sigh J, Buchmann K, Tinsley RC (2003) Immunization of rainbow trout Oncorhynchus mykiss against Discocotyle sagittata (Monogenea). Dis Aquat Org 55:23-30

Thoney DA, Burreson EM (1988) Lack of a specific humoral antibody response in Leiostomus xanthurus (Pisces: Sciaenidae) to parasitic copepods and monogeneans. J Parasitol 74:191-193

Thoney DA, Hargis WHJ (1991) Monogenea (Platyhelminthes) as hazards for fish in confinement. Annu Rev Fish Dis 1: 133-153

Vladimirov VL (1971) The immunity of fishes in the case of dactylogyrosis. Parasitologiya 5:51-58 (in Russian)

Wang G, Kim JH, Sameshima M, Ogawa K (1997) Detection of antibodies against the monogenean Heterobothrium okamatoi in tiger puffer by ELISA. Fish Pathol 32:179-180

Williams H, Jones A (1994) Parasitic worms of fish. Taylor \& Francis, London

Submitted: April 14, 2003; Accepted: June 16, 2003

Proofs received from author(s): August 11, 2003 